\title{
Leadership for management of high-level radioactive waste in Japan
}

Maria R. H. Takeuchi

$\mathrm{PhD}$ candidate, Graduate School of Energy Science, Kyoto University, Kyoto, Japan (corresponding author: takeuchi.hisae.37a@kyoto-u.jp) Tatsuya Hasegawa

Professor, Institute of Materials and Systems for Sustainability, Nagoya University, Nagoya, Japan

\author{
Susie M. L. Hardie \\ Senior Environmental Chemist, CSD Ingenieure AG, Aarau, Switzerland \\ Linda E. McKinley \\ Partner, McKinley Consulting, Frick, Switzerland \\ Keiichi N. Ishihara \\ Professor, Graduate School of Energy Science, Kyoto University, Kyoto, Japan
}

High-level radioactive waste (HLW) management in Japan stalled prior to selecting any candidate sites for a literature survey, the first step of a staged programme for selecting a disposal site. The situation deteriorated after the Fukushima Daiichi accident. The Nuclear Waste Management Organization of Japan has suffered a loss of national/international credibility in the geological disposal project. In this study, the authors first examine the history of HLW management in Japan, assess how leaders in different key organisations communicated with each other and identify the rationale for the resulting characteristics of the overall programme. The objective is to investigate the problems encountered and the solutions adopted from a perspective that highlights what were, in retrospect, missed opportunities. A further goal is to look to the future and, from lessons learned, to determine a leadership role to allow HLW management to move forward for the next stage of selecting candidate sites. Communication for correct scientific input between leaders of relevant organisations is of critical importance. Alliance with key organisations and commitment by the government are also required. To win credibility and sympathy with geological disposal, ethical responsibilities should be taken by leaders of these organisations. The authors assume that the quality of HLW management could be enhanced by servant leadership.

\section{Introduction}

In Japan, a range of different types of radioactive wastes is generated from nuclear power production and various other nuclear applications (e.g. in medicine, industry and research). In many countries around the world with advanced nuclear programmes, it is considered an ethical responsibility of the current generation (those that have benefitted from the use of nuclear technologies) to prepare for, and ensure the implementation of, safe disposal of this waste, without passing on the burden to future generations. Highlevel radioactive waste (HLW), such as spent fuel from nuclear power plants or vitrified waste resulting from its reprocessing, must be isolated from humans and the environment for extremely long periods until it is no longer hazardous to life and the environment. Since the first discussions in the USA during the 1950s, geological disposal has been accepted worldwide as the most feasible option for the long-term management of HLW, regardless of the pros and cons of nuclear power generation (Tochiyama and Masuda, 2013). Finland is the first country in the world that selected a site for HLW repository due to their 'well-defined, sufficiently fair process, which the main stakeholders could accept and follow' (Vira, 2006). Sweden has recently made great progress, and some other countries (e.g. Switzerland and France) also have advanced programmes (NUMO, 2017a; SKB, 2017)

Currently, HLW management in Japan has stalled prior to selecting any candidate sites for a literature survey, the first step of a staged programme for selecting a disposal site, and those concerned therefore need to find a way to move forward. Despite suffering from atomic bombs during World War II, nuclear power was seen as a necessary requirement for meeting Japan's energy needs due to its limited domestic sources of alternative power. This situation of reluctant acceptance changed after the Fukushima Daiichi meltdown caused by the earthquake and tsunami in 2011, resulting in general public opposition to constructing and/or operating nuclear power stations (Gallardo et al., 2014; Masaki, 2012). Regardless of the future of nuclear power in Japan, the fundamental requirement to dispose of current inventories of radioactive waste sometime in the future remains. Japan has already generated a lot of radioactive waste and may continue to generate more. In order to achieve the goal of safe disposal, a created vision for sustainable strategy by leaders became more important after the Fukushima Daiichi accident. For implementation of geological disposal, scientific aspects related to available technology, operational safety and possible risks in the far future must be examined, discussed and balanced with sociopolitical aspects related to established policies and, in particular, public and political acceptance. Over the past three decades, extensive work has been carried out to establish a strong scientific and technological basis for disposal in Japan, with addition of wider consideration of how to build technical and social confidence and promote public acceptance since the beginning of this century (Juraku, 2013; Kimura et al., 2003; Komine, 2004; Tochiyama and Masuda, 2013; Wakasugi et al., 2012; Yoshida et al., 2014).

According to the original plan of the implementing organisation for HLW management (NUMO, 2004a), fieldwork should have started a decade ago and they should now be at the stage of repository licensing. Despite the general consensus on the need to move forward, even before the Fukushima Daiichi accident, the process 
Environmental Geotechnics

Volume 7 Issue 2
Leadership for management of high-level

radioactive waste in Japan

Takeuchi, Hasegawa, Hardie, McKinley and Ishihara

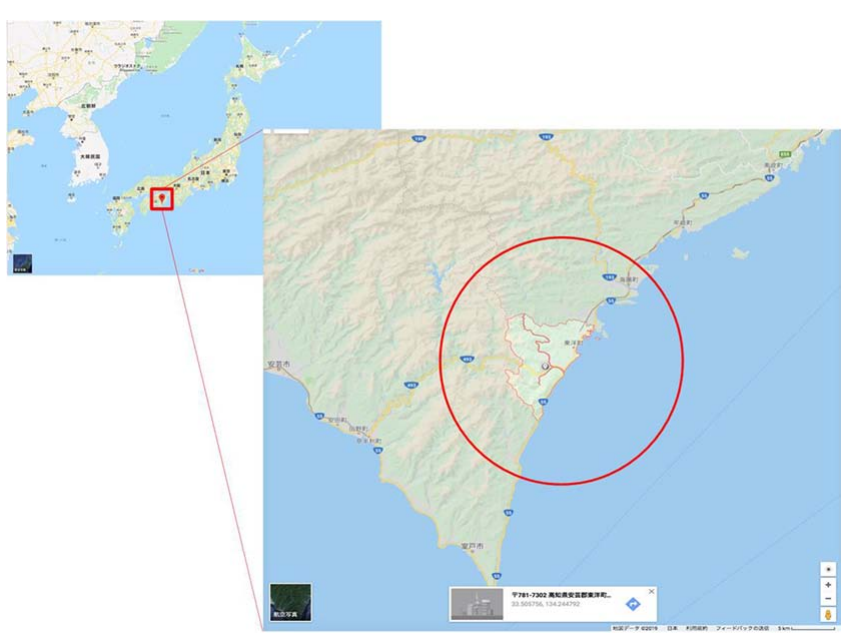

Figure 1. Diagram of Toyo Town that applied for literature survey for HLW disposal (Map data used by permission from Google, Maxar Technologies)

for selecting candidate sites for a literature survey based on a call for volunteers failed, as no communities came forward. The closest case of a volunteer involved Toyo Town in Kochi Prefecture (Figure 1), although it eventually withdrew its application for a literature survey in 2007. Japanese researchers have analysed the political process and the decision-making process of the citizens of Toyo Town and investigated the causes of failure (Saigo et al., 2010; Wada et al., 2009). The importance of participation of various stakeholders and the miscommunication with non-expert stakeholders have been discussed so far. The development and implementation of a geological repository involves evolving multidisciplinary projects running over a period of up to about 300 years (including possible monitoring and institutional control), for which there is internationally no precedent. This is coupled to the equally challenging job of building and maintaining acceptance by a wide range of stakeholders, including, in particular, the host communities.

In this study, the authors first examine the history of HLW management in Japan, assess how leaders/decision makers in different key organisations communicated with each other and identify the rationale for the resulting characteristics of the overall programme. The objective here is to investigate the problems encountered and the solutions adopted from a perspective that highlights what were, in retrospect, missed opportunities. A further goal is to look to the future and, from lessons learned, to determine a leadership role to allow HLW management in Japan to move forward to the next stage of selecting candidate sites to be investigated as potential repository hosts.

\section{History of HLW management in Japan}

HLW management prior to 2000

The Power Reactor and Nuclear Fuel Development Corporation (PNC) was established in 1967 as the core organisation for the nuclear fuel cycle, including research and development (R\&D) on HLW treatment and disposal. PNC ran under the supervision of the Science and Technology Agency (STA, now the Ministry of Education, Culture, Sports, Science and Technology). At that time, the Agency for Natural Resources and Energy (ANRE) of the Ministry of Economy, Trade and Industry (METI) was responsible for matters associated with commercial nuclear power plants, while the STA covered other nuclear issues. Since HLW was managed outside commercial nuclear power plants, STA was responsible for it.

PNC established the fundamental feasibility of HLW disposal in Japan in the seminal 'H3' project, the documentation of which was also translated into English (PNC, 1992) and was, at the time, considered to represent the international state of the art in this field. PNC or the Japan Nuclear Cycle Development Institute (JNC) (PNC was subsequently reorganised in 1998 as JNC) also developed extensive world-class $R \& D$ infrastructure to support the geological disposal project - including in particular underground research laboratories and the Entry and Quality facilities at Tokai. This was complemented by R\&D carried out by a range of other Japanese organisations (e.g. Radioactive Waste Management Funding and Research Center (RWMC), Central Research Institute of Electric Power Industry and Japan Nuclear Energy Safety Organisation) and universities. Formally, some of this work could be considered as supporting either a future repository implementer or a regulator, but the distinctions were unclear as research topics tended to be defined in a bottomup manner with little or no top-down technical coordination of this work.

Outside the geological disposal field, confidence in PNC suffered due to a series of accidents in their facilities, including a sodium leak accident and subsequent fire at the Monju prototype fast breeder reactor located in Fukui Prefecture in 1995 and another accident at the Tokai nuclear fuel-reprocessing plant located in Ibaraki Prefecture in 1997. Here it should be noted that concerns arose not only from technical failings, but also from the lack of openness and communication (Kondo, 2017; Mikami et al., 1996).

Around this time, the governors of Fukushima, Niigata and Fukui Prefectures, where key nuclear power plants are located (the generating capacity of the nuclear power plants in these three prefectures was about $50 \%$ of the total capacity of the nuclear power plants in Japan), required the Japanese government to constitute a law for final disposal of radioactive waste. This involved interaction with the Federation of Electric Power Companies of Japan (FEPC), an organisation of the electricity utilities in Japan established to smooth the operation of the plants and, in particular, to promote nuclear power generation. STA did not feel capable of managing such interaction and thus requested the director of ANRE to take over full responsibility for constituting this law. This resulted in the drafting of the Specified Radioactive Waste Final Disposal Act (hereafter the Final Disposal Act) by ANRE (MIC, 2000). 


\section{H12 report}

The Japanese R\&D programme for geological disposal initially focused on vitrified HLW from reprocessing of spent fuel based on a national policy requiring recycling of all uranium (U) and plutonium $(\mathrm{Pu})$ for reuse in reactors. This was the waste 'specified' in the Final Disposal Act, and, to support this, progress since $\mathrm{H} 3$ was summarised in the second progress report, entitled H12: Project to Establish the Scientific and Technical Basis for HLW Disposal in Japan (JAEA, 1999). The objectives of the H12 study were to reconfirm the technical basis for assuring the reliability of geological disposal in Japan and to provide input to the siting and regulatory procedures following the initial $R \& D$ phase. This report was submitted to the Atomic Energy Commission (AEC) of Japan in 1999. H12 was also translated into English, and an international peer review was carried out by the Nuclear Energy Agency (NEA) prior to its submission. The general conclusion of the review was that the generic technical basis for geological disposal in Japan had been comprehensively documented and convincingly assessed. This provided a sufficient level of confidence that the tools and system understanding had been developed to justify proceeding to the next phase of site selection and characterisation (NEA, 1999).

In parallel, R\&D for transuranic (TRU) waste (a range of higheractivity radioactive waste generated during reprocessing and mixed-oxide fuel fabrication) was summarised for a concept of geological disposal using the H12 knowledge base combined with experience in disposal of other types of lower-activity waste at Rokkasho (JNC and FEPC, 2000).

\section{Establishment of the Nuclear Waste Management Organization of Japan}

The Nuclear Waste Management Organization of Japan (NUMO) was established in 2000, in accordance with the Final Disposal Act (authorised by METI) as the implementing organisation for the geological disposal of specified radioactive waste (initially HLW, expanded to include TRU waste in 2008 (NUMO, 2008)). Since NUMO has no research facilities, JNC (renamed Japan Atomic Energy Agency in 2005), other R\&D organisations and Japanese universities provide scientific support to NUMO. NUMO initiated invitation of applications for a literature survey for HLW disposal in 2002. The site selection procedure specified in the Final Disposal Act consists of three steps - namely, a literature survey, preliminary investigations and detailed investigations. At each stage in the site selection process, NUMO will compile reports on the investigation results and will hold explanatory meetings. The opinions of local people expressed at these meetings will be made known to the relevant prefectures and municipalities together with NUMO's views, and selection will proceed on the basis of respecting local opinions, obtaining stakeholder agreement and securing government approval. The government has stipulated that when approving each stage of the site selection process, the opinions of the municipality mayors and the governors of the prefectures concerned must be listened to and respected. Selections that oppose these views will not take place (NUMO, 2002).
Rapid development guided by the advisory committee and supported by bilateral agreements

NUMO established the International Technical Advisory Committee (ITAC) in June 2001, with the intention of transferring know-how from other national disposal programmes to the Japanese programme and ensuring that NUMO's technical work is of an appropriate international standard. ITAC complemented NUMO's Domestic Technical Advisory Committee by providing input that contributed to technical and scientific accuracy, openness, transparency and traceability in NUMO's technical programme (NUMO, 2001). NUMO also established bilateral links with some of the most advanced national waste-management programmes (National Radioactive Waste Management Agency, National Cooperative for the Disposal of Radioactive Waste, Posiva, Swedish Nuclear Fuel and Waste Management Company, US Department of Energy and RWMC) and initiated several active collaboration projects with these partners, aimed at both knowledge transfer and staff training.

\section{Innovative siting factors and repository concept catalogue}

In TR-04-03 (NUMO, 2004a), NUMO developed and described a catalogue of 'repository concepts' that illustrated the tailoring to potential volunteer sites of not only the design and layout of the disposal system, but also the associated evaluation of operational and long-term safety and assessment of socio-economic aspects. An associated study showed how the volunteering approach to siting should be constrained by the use of 'siting factors' (NUMO, 2004b) that ensure that only locations that have sufficient geological stability are considered - an important factor in a country such as Japan, which lies in a tectonically active region (NUMO, 2004a). Both these English summary reports of larger Japanese studies were well received internationally and, indeed, served as models for other programmes that followed NUMO in the volunteering approach to siting. Despite rapidly establishing international technical recognition, the most difficult problem of communicating disposal safety to key stakeholders, in particular non-technical decision makers and the general public, remained unsolved by NUMO.

\section{Illustration of implementation problems: the Toyo Town case study}

Stepwise siting in Japan is initiated by community acceptance of a literature survey to determine if there are any fundamental blocks on it being considered further, such as major active faults or evidence of Quaternary volcanism in the vicinity. Even if a volunteer clears this first hurdle, they cannot move on to the next stage of the preliminary investigation (including surface-based geophysics and drilling boreholes) if this is not accepted by citizens as represented by the mayor of the community or the governor of the prefecture.

Toyo is a small town in Kochi Prefecture of Shikoku in Japan. The town's population is only about 3400 , and the budget for the fiscal year 2006 was around $¥ 2$ billion (about US\$20 million). 
The town was in serious financial straits, and the mayor of the town applied for a literature survey for HLW disposal in March 2006 with the aim of benefitting from the associated subsidies: municipalities that accepted a literature survey would receive $¥ 210$ million (raised to $¥ 1$ billion from 2007) over 2 years. The mayor of Toyo Town hoped that the town would develop support industries and employment with this large investment, leading to improvement of living standards. As the literature survey could be applied for based on the mayor's judgement, he submitted the application form to NUMO without discussion with the local council (his rash behaviour later incurred the distrust of local people and he regretted this). NUMO suggested that he should apply after discussing the issue with the local council and organising some workshops for citizens. He asked NUMO to return the application form at the end of March. To gain the understanding of local people and communicate and share his vision with them, he organised the first workshop in August with all the members of the local council, some town officials, the general manager of the public relations department of NUMO and others. During the following month, not only local people but also anti-nuclear groups from other prefectures mobilised to object to the literature survey with general support from the media. The anti-nuclear movement deliberately focused on building opposition to siting a repository in Toyo Town (not against the literature survey as such). In this regard, the local populace suffered from a lack of opportunity to develop an unbiased understanding of technical issues associated with siting and operating a repository and the arguments for its long-term safety. Finally, the mayor decided to apply based on his political judgement without further discussion with the local people, submitting the application form to NUMO on 25 January 2007. This was the only local government application for a literature survey. The council of Toyo Town adopted a resolution to demand the mayor's resignation on 9 February. He resigned on 5 April and called for a snap election. He suffered a crushing defeat on 22 April, and the newly elected anti-nuclear mayor withdrew the application on 23 April 2007 (Saigo et al., 2010; Tashima, 2008; Wada et al., 2009).

In retrospect, Toyo Town's case can be seen to be similar to experience in other countries where, even at the very earliest stages of characterisation of potential sites, opponents immediately focus on concerns related to repository safety regardless of how premature this may be. This has proven difficult for implementers to counter when disposal concepts are still at a very basic, generic stage. It is clear, however, that a much more active, comprehensive and user-friendly approach to communication is required, which needs concerted efforts from not only implementers but also regulators (to establish their own credibility), the government and the 'nuclear community' within the utilities, R\&D organisations and universities.

\section{Developments since 2007}

No volunteer communities have come forward since Toyo Town, and the programme has been continually losing momentum, in particular since the Fukushima Daiichi accident in 2011 (Table 1). Negative opinions toward nuclear power generation in Japan supporting 'abolition or reduction', which used to be $20-30 \%$ over the past 30 years, increased to $70 \%$ from 4 to 6 months after the accident (Kitada, 2013).

In an attempt to attract volunteers, the Japanese government reviewed and improved the relevant policy in 2015 and published the Nationwide Map of Scientific Features for Geological Disposal ('Nationwide Map') (NUMO, 2017b) on 28 July 2017, which divided all areas in Japan into four categories - namely, $(a)$ areas with unfavourable geological features that may damage the long-term stability of the geological environment, $(b)$ areas with natural resources, (c) areas with a good chance of being confirmed as having favourable characteristics and $(d)$ areas within $(c)$ that are also favourable from the viewpoint of waste transportation (NUMO, 2017c). NUMO started to organise events to exchange opinions about the publicised map for geological disposal with the general public in 46 prefectures in Japan. This initiative showed that it was recognised that the government had to play a more active role, and an international review by the NEA was included at an early stage.

\section{Methodology}

A literature review was undertaken based on key papers and reports on HLW management in Japan and the book written in Japanese Nuclear War in a Small Town No One Knew (Tashima,

Table 1. Chronological order of events in the establishment of HLW disposal in Japan

\begin{tabular}{|c|c|}
\hline Year & Important events \\
\hline 1967 & PNC was established as the core organisation for the nuclear fuel cycle, including R\&D on HLW treatment and disposal. \\
\hline 1992 & $\begin{array}{l}\text { PNC established the fundamental feasibility of HLW disposal in Japan in the seminal H3 project, the documentation of which was also } \\
\text { translated into English. }\end{array}$ \\
\hline 1998 & STA requested the director of ANRE of METI to take over full responsibility for constituting the Final Disposal Act. \\
\hline 1999 & $\begin{array}{l}\text { The } \mathrm{H} 12 \text { report was submitted to AEC of Japan. } \mathrm{H} 12 \text { was also translated into English, and an international peer review was carried out } \\
\text { by the NEA prior to its submission. }\end{array}$ \\
\hline 2000 & $\begin{array}{l}\text { NUMO was established, in accordance with the Final Disposal Act (authorised by METI) as the implementing organisation for the } \\
\text { geological disposal of specified radioactive waste. }\end{array}$ \\
\hline 2007 & Toyo Town, the only local government that applied for a literature survey, withdrew its application. \\
\hline 2011 & The Fukushima Daiichi accident happened. \\
\hline 2017 & The Japanese government published the Nationwide Map of Scientific Features for Geologica \\
\hline
\end{tabular}


2008), authored by Mr Yasuoki Tashima, the then mayor of Toyo Town who promoted acceptance of the literature survey. This review was complemented by interviews (conducted between March 2017 and May 2018) with three key persons - (a) the director of ANRE of METI, who was requested to take over full responsibility for constitution by STA in 1998 and created the draft of the Final Disposal Act as the administrative leader (directors of the ministries hold real power in Japan); (b) the technical leader of Tokyo Electric Power Co., Inc. (Tepco) for HLW management, who had been developing new methods to ensure safety and introducing Japanese technological strategies to international experts (Ichikawa et al., 1999a, 1999b; Kitayama et al., 2007) between 1995 and 2000 (Tepco was the lead company among electric power utilities in Japan before the Fukushima Daiichi accident) and was also the technical leader of NUMO between 2000 and 2008; and (c) the current key official of ANRE responsible for the management of HLW disposal - as well as discussions (conducted between May 2017 and May 2018) with a number of officials of METI, members of NUMO and international Technical Advisory Committee (TAC) members, who have been transferring know-how from other national disposal programmes to the Japanese programme and ensuring that NUMO's technical work is of an appropriate international standard (NUMO restarted their TAC in 2015, which includes both Japanese and international experts).

Those interviewed were as follows

(a) Mr Masanori Suzuki, director of the Nuclear Industry Division of ANRE of METI between 1997 and 2000

(b) Dr Kazumi Kitayama, technical leader of Tepco for HLW management between 1995 and 2000, then director of the Science and Technology Department of NUMO between 2000 and 2008

(c) Mr Shinichi Kijima, deputy director of ANRE of METI, who is currently responsible for the management of HLW disposal.

\section{Summary of the interviews}

\section{Director of ANRE of METI}

As the director of the Nuclear Industry Division of ANRE between 1997 and 2000, Mr Suzuki points out that the hardest obstacle was to align the personnel of FEPC to build consensus on their responsibility for HLW management because it was not the electric power companies but the Japanese government that promoted nuclear fuel cycle policy (Anon, 1993). The electric power companies therefore believed that the Japanese government was responsible for HLW management. Scientific input to confirm the technical basis for assuring the reliability of geological disposal in Japan was provided by the staff of various organisations, and opinions varied from person to person. $\mathrm{Mr}$ Suzuki does not remember whether he had read JNC's H12 report or its draft or the NEA's international review before ANRE drafted the Final Disposal Act. He never met Dr Kitayama, who had been the technical leader for HLW management since 1995.
ANRE thought Japan was behind in scientific research for HLW management compared with leading countries such as Finland and Sweden. Due to a lack of data obtained through experiments using radioactive materials, reliability of safe disposal was considered low and ANRE was not able to include a regulation that ensures safe disposal in the Final Disposal Act. This was clearly a fundamental problem.

\section{Technical leader of Tepco/director of NUMO}

Dr Kitayama's direct involvement with HLW disposal started with his role supporting the establishment of an implementing organisation while at Tepco between 1995 and 2000 and, thereafter, serving as the head of the NUMO science and technology division between 2000 and 2008. His impression is that the Final Disposal Act was not formulated appropriately with regard to the selection of preliminary investigation areas based on literature surveys, as it requires that the Minister of Economy, Trade and Industry should 'listen to the opinions of the governor of the candidate prefecture and the mayor of the candidate municipality and respect them sufficiently' even before starting the first step of a literature survey. He believes that such surveys should be conducted without any formal consent since the literature involved is already openly published (Kitayama, 2013; Kitayama and Kikura, 2013). If this had been the case, first communication with local communities could be tailored to their particular boundary conditions and thus provide a sound basis for discussion of any of their concerns with regard to the following field investigations, site selection and eventual repository implementation.

The draft of the act was created by ANRE officials without input from Dr Kitayama. NUMO was the nominated implementing organisation, but it was expected to move forward with siting without direct support by the government or any other organisations (e.g. regulators, local utilities and nuclear R\&D agencies), which contrasts with the wider basis of siting in other successful national waste-management programmes.

In addition, NUMO had difficulties in communicating with the local people of Toyo Town because of the involvement of NUMO public relations staff with little understanding of geological disposal and the scientific basis of the safety case. Although Dr Kitayama recognised this problem and the risk of losing public acceptance, his opinion was ignored. He regretted not having breathed life into his project.

\section{Deputy director of ANRE of METI}

As the deputy director of ANRE (since 2017), who is currently responsible for the management of HLW disposal, Mr Kijima claims that very low awareness of geological disposal of HLW is the biggest problem in Japan. He therefore thinks it was meaningful to publish the Nationwide Map by the Japanese government to let people see the category in which their city/ town/village is placed. He believes that it is crucial to improve awareness among the general public first. He is willing to support NUMO and is positive about the activities to exchange opinions about the Nationwide Map with the general public. 


\section{Results and discussions}

Lack of communication between leaders/decision makers and alliance

Implementing geological disposal involves balancing a number of technical and sociopolitical requirements. Thus, it is important that all key actors - the government (at all levels), implementers and regulators plus their supporting technical experts - are aware of the issues involved. According to the interviews, prior to drafting of the Final Disposal Act, there was no communication between the director of ANRE and the technical leader of Tepco (who later became the technical leader of NUMO), who could have provided scientific context and justifications to assure any stakeholders of the fundamental safety of such disposal. There seemed to be no connection between ANRE and JNC, which was the key nuclear R\&D organisation that could also have provided scientific input.

Actual scientific input to confirm the technical basis for assuring the reliability of geological disposal in Japan was provided to ANRE by various organisations, but opinions varied from person to person and were considerably influenced by their understanding of progress in other advanced national programmes. Recognition of the importance of public acceptance based on international experience was captured and led to the policy of volunteering as a key to initiation of repository siting - a novel approach that was positively received and copied by other programmes (e.g. Canada and the UK). However, as seen from Mr Suzuki's comments, there was a general lack of understanding of the different international boundary conditions and how these influenced programme implementation. The then leaders did not discuss thoroughly how safety could be demonstrated and how the volunteering process should be implemented prior to drafting of the Final Disposal Act. Dr Kitayama claimed that the Final Disposal Act drafted by ANRE alone became a very big obstacle to the initial literature survey for HLW disposal. One of the international TAC members pointed out that there is general agreement with Dr Kitayama's points with regard to both the literature survey without a local permitting process (this is the norm internationally) and the fundamental basis of programmes with siting by nomination rather than volunteering, although with increasing involvement of local communities as site selection proceeds. Related technical communication is certainly more effective if supported by a site-specific knowledge base and must involve technical staff with wide backgrounds and required communication skills. Such messages were clear from a recent seminar run by NUMO that featured input from its international TAC members. (The record of the first meeting held in November 2015 was published (NUMO, 2015)).

The international review of the NEA in 1999 reported that special complexities affected the H12 study because of its wide scope of diverse geological and surface environments, leading to very conservative assumptions about site conditions. Safety assessment could thus be more realistic for the lower uncertainties associated with site-specific databases. In order to narrow down suitable areas for disposal, it would have been prudent to discuss whether the Japanese implementing organisation could conduct literature surveys based on published literature without a local permitting process before the Final Disposal Act was created. In fact, the reliability of safe disposal was considered low by ANRE, and the act stipulates that selection of preliminary investigation areas based on literature surveys require that the Minister of Economy, Trade and Industry should 'listen to the opinions of the governor of the candidate prefecture and the mayor of the candidate municipality and respect them sufficiently' (MIC, 2000). This results in a 'catch-22' situation where lack of understanding of the arguments for safety from generic assessments results in resistance to site-specific characterisation of the type that would allow safety margins to be assessed realistically and hence increase acceptance. As a result, no survey has yet been conducted and the HLW-management programme has been on indefinite hold.

As Mr Suzuki said, it was very hard for the Japanese government/ ANRE to align FEPC to build consensus on their responsibility for HLW management because it was not the electric power companies but the Japanese government that promoted nuclear fuel cycle policy, and, thus, the electric power companies and FEPC believed the Japanese government was fully responsible for this area. Here an important point is that no distinction was made between establishing policy and implementing it. Although it is clearly a role of the government to set policy, it is evident that countries (e.g. Sweden) where major progress has been made have strong, relatively independent implementers and regulators together with committed support by the utilities (NEA, 2012a). Without such an alliance, they could not move forward.

Although both the director of ANRE and the technical director of NUMO tried to push HLW management forward, the required infrastructure was missing and implementation of possible improvements was blocked by lack of communication and alliance. This situation is evident in the case of Toyo Town. The mayor, who was trying to devote himself to the development of Toyo Town, submitted the first application to NUMO without discussion with the members of the local council. Local people, including the decision makers of the town, considered that the mayor and NUMO were 'talking money' for siting without transparency and had doubts about their ethical responsibilities. In addition, there was no alliance and the mayor could not obtain strong support by the government, NUMO, local utilities and nuclear R\&D organisations, who could have helped explain the strength of the safety case to local communities (Tashima, 2008). Indeed, how can the general public trust the safety of disposal before all leaders/decision makers are clearly convinced of this?

\section{Leaders' actions to win credibility and sympathy with geological disposal}

Even recent signs of government support, such as the Nationwide Map, reflect a lack of understanding of the history of the Japanese 
programme (such a map was already developed by NUMO in 2004) and unpreparedness to commit to making major changes in the programme in order to break the present logjam. NUMO recognised that an integration of additional, more refined techniques would be required to evaluate sites that pass the minimum site acceptance criteria (related to earthquake risk and active faults, igneous activity, uplift and erosion, unconsolidated Quaternary sediments and mineral resources). In particular, tools for quantitative assessment of the likelihood and potential impacts of tectonic events and processes at any site are required. A major project for developing such methodology for the specific conditions of Japan based on state-of-the-art approaches used internationally (eventually termed 'Topaz' (Tectonics of Potential Assessment Zones)) was thus initiated and has been described in both the open literature and in NUMO technical reports (Chapman et al., 2012; NUMO, 2017d). Despite the consensus from both domestic and international experts that this formed a sound basis for assessing risks from 100000 years out to 1 million years and illustration of its application to a number of regions in Japan, such output was not reflected in the Nationwide Map published in 2017 and is little known by non-technical stakeholders in 'preferable' siting areas. Despite its technical content, it is clear that NUMO needs to communicate this work to ANRE to support selection of suitable areas and, together, ensure that key messages are understood by key decision makers.

The bottom line is that effective communication of technical issues, in particular for decision makers, is essential to make progress with such a technically complex and sociopolitically sensitive project. Alliance with key organisations and commitment by the government are also required, but the implementer (and regulator) requires freedom to implement policy in a flexible manner: if this is not assured, regardless of communication, key decisions will be stalled by Nimto (not-inmy-term-of-office) considerations as seen in many other past cases around the world.

It was unfortunate that the NUMO programme was disrupted after the Fukushima Daiichi accident in 2011, with key technical staff moved to other organisations. NUMO suffered loss of national/ international credibility of the geological disposal project, resulting from loss of confidence in the entire Japanese nuclear industry. NUMO needs to find a way to promote public acceptance and move forward. Tochiyama and Masuda (2013) conclude that the politician's role is the most critical for the solution of the HLW-management issue, and Masuda (2016) points out the role of policymakers as mediators between the implementing organisation and the general public. The need for leadership by NUMO was argued by the Advisory Committee on Radioactive Waste of the Japan AEC (2016) and is emphasised again in the master plan for R\&D for geological disposal between 2018 and 2023 (METI, 2018). Many experts recognised the need for leadership to move forward, but no one has given shape to leadership for HLW management.
In the case of Toyo Town, local people considered that the leaders were talking money for siting without transparency, and, thus, both NUMO and the mayor failed in winning credibility, as discussed in the previous section (Tashima, 2008). Whenever some leaders in the Japanese nuclear industry tried to cover up the causes of the accidents, including Fukushima, the population criticised their secretive nature (Anon, 2017). They could not believe that such leaders took ethical responsibilities towards society seriously.

To win credibility and sympathy for geological disposal, ethical responsibilities should be borne in the first place by leaders/ decision makers of relevant organisations. How then can leaders take ethical responsibility?

In the report of the NEA, the importance of societal and ethical responsibilities taken by waste-management organisations and safety authorities is emphasised. As behavioural features to be addressed, openness, transparency, honesty, consistency, willingness to be tested, freedom from arrogance, recognition of limits, commitment to a highly devoted and motivated staff, coherence with organisational goals, an active search for dialogue and an alert listening stance and caring attitude are enumerated (NEA, 2012b).

A huge number of studies on leadership, including in political and social movements and complex organisations, are introduced by Bass (2008), and there are numerous studies of public or publicsector leadership (e.g. Van Wart, 2003; Vogel and Masal, 2015).

Among the many theories, the authors direct their attention to servant leadership as formulated by Robert K. Greenleaf (1977), which embodies the aforementioned behavioural features and seems to be most applicable to Japan's case. The major characteristic of the servant leadership theory is the emphasis on ethical responsibilities to followers, stakeholders and society (Van Wart, 2003). According to Greenleaf, the servant-leader is servant first. It begins with the natural feelings that one wants to serve. The person who is leader first later serves out of promptings of conscience or in conformity with normative expectations. Greenleaf (1977: p. 24) explains, 'Those who choose to follow this principle will not casually accept the authority of existing institutions. Rather, they will freely respond only to individuals who are chosen as leaders because they are proven and trusted as servants'. The authors assume that the quality of management in a public-sector area, such as HLW management, could be enhanced by servant leadership. To servant-leaders, both the means of siting and the goal of safe disposal are equally important. The ends do not justify the means. They do not manipulate information or people. The major problems of each key organisation and their causes are summarised in Figure 2. To solve these problems, the authors will further discuss how to enhance the quality of management in the future based on leadership theories in a different paper. 


\begin{tabular}{l|l|}
\hline $\begin{array}{l}\text { Key } \\
\text { organisations }\end{array}$ & Major problems \\
\hline ANRE & $\begin{array}{l}\text { - Lack of understanding of scientific context and } \\
\text { justifications to assure any organisation of the } \\
\text { fundamental safety of disposal } \\
\text { - Lack of understanding of the different international } \\
\text { boundary conditions and how these influenced } \\
\text { programme implementation }\end{array}$ \\
\hline NUMO & $\begin{array}{l}\text { - The Final Disposal Act enacted in } 2000 \text { became a very } \\
\text { big obstacle to the initial literature surveys for HLW } \\
\text { disposal }\end{array}$ \\
& $\begin{array}{l}\text { Had difficulties in communicating with the local people } \\
\text { of Toyo Town and failed in winning credibility } \\
\text { - Lack of opportunity to develop an unbiased } \\
\text { understanding of technical issues associated with } \\
\text { siting and operating a repository and the arguments } \\
\text { for its long-term safety and failed in winning credibility }\end{array}$ \\
\hline Toyo Town &
\end{tabular}

Cause 1: lack of communication between leaders of key organisations

Cause 2: lack of alliance with

key organisations

Cause 3: not getting people to

believe ethical responsibilities

taken to society

Figure 2. Summary of the problems in each key organisation and the relationship to three main causes

\section{Conclusions}

The authors examined the history of HLW management in Japan and found five major problems with the key organisations. Their causes can be summarised as around three points, which are all related to leadership: (a) lack of communication between the leaders of key organisations, (b) lack of alliance with key organisations and (c) failing to convince people of the ethical responsibilities taken towards society. Effective communication for correct scientific input between leaders/decision makers of relevant organisations is of critical importance. Alliance with key organisations and commitment by the government are also required. To win credibility and sympathy with geological disposal, ethical responsibilities should be borne in the first place by leaders/decision makers of those organisations. The authors assume that the quality of management in a public-sector area, such as HLW management, could be enhanced by servant leadership.

\section{Acknowledgements}

The authors wish to thank Dr Kazumi Kitayama and Mr Masanori Suzuki for their time and frankness in granting extensive interviews on this topic.

\section{REFERENCES}

AEC (Atomic Energy Commission) (2016) Saisyu syobun kannkei gyousei kikantou no katsudou jyoukyou ni kansuru hyouka houkokusyo. AEC, Tokyo, Japan (in Japanese). See http://www.aec.go.jp/jicst/NC/ senmon/hosya_haiki/houkoku.pdf (accessed 26/01/2018).

Anon (1993) Nuclear energy and its fuel cycle in Japan: closing the circle. IAEA Bulletin, September: pp. 34-37. See https://www.iaea.org/ sites/default/files/35304893437.pdf (accessed 26/01/2018).

Anon (2017) Concealment of reactor core meltdown, denial of instruction of official residence TEPCO/Niigata Prefecture verification committee: survey result of Fukushima nuclear power plant accident. Nikkei (Nihon Keizai Shimbun), 26 December (in Japanese). See https://www. nikkei.com/article/DGXMZO25077350W7A221C1000000/ (accessed 26/01/2018)

Bass BM (2008) The Bass Handbook of Leadership: Theory, Research, and Managerial Applications, 4th edn. Free Press, New York, NY, USA.
Chapman N, Apted M, Aspinall W et al. (2012) TOPAZ Project: Longterm Tectonic Hazard to Geological Repositories - an Extension of the ITM Probabilistic Hazard Assessment Methodology to 1 Myr. Nuclear Waste Management Organization of Japan, Tokyo, Japan, NUMO TR12-05. See https://www.numo.or.jp/technology/technical_report/ tr12_05pdf/TR-12-05.pdf (accessed 26/01/2018).

Gallardo AH, Matsuzaki T and Aoki H (2014) Geological storage of nuclear wastes: insights following the Fukushima crisis. Energy Policy 73: 391-400, https://doi.org/10.1016/j.enpol.2014.05.018.

Greenleaf RK (1977) Servant Leadership: a Journey into the Nature of Legitimate Power and Greatness. Paulist Press, New York, NY, USA.

Ichikawa Y, Kawamura K, Nakano M and Kitayama K (1999a) Unified molecular simulation/homogenization method - an analysis of bentonite clay in high-level radioactive waste management. NihonGenshiryoku-Gakkai Shi (Journal of the Atomic Energy Society of Japan) 41(2): 88-97 (in Japanese).

Ichikawa Y, Kawamura K, Nakano M, Kitayama K and Kawamura H (1999b) Unified molecular dynamics and homogenization analysis for bentonite behavior: current results and future possibilities. Engineering Geology 54: 21-31, https://doi.org/10.1016/S0013-7952(99)00058-7.

JAEA (Japan Atomic Energy Agency) (1999) H12 Report. JAEA, Ibaraki, Japan. See https://www.jaea.go.jp/04/tisou/english/report/H12_report. html (accessed 20/04/2017).

JNC (Japan Nuclear Cycle Development Institute) and FEPC (Federation of Electric Power Companies of Japan) (2000) Concept of Disposal for TRU Wastes. Japan. JNC-TY1400-2000-001 (in Japanese). See http:// jolissrch-inter.tokai-sc.jaea.go.jp/pdfdata/JNC-TY1400-2000-001.pdf (accessed 26/04/2017).

Juraku K (2013) Towards 'value judgment' discussions; cases of nuclear safety, high-level radioactive waste management and the role of AESL. Nihon-Genshiryoku-Gakkai Shi (Journal of the Atomic Energy Society of Japan) 55(10): 582-586 (in Japanese).

Kimura H, Furuta K and Suzuki A (2003) Psychological factors affecting public acceptance of nuclear energy: comparative analysis focusing on regional characteristics and degree of knowledge. Nihon-GenshiryokuGakkai Wabunronbun Shi (Transactions of the Atomic Energy Society of Japan) 2(4): 379-388 (in Japanese), https://doi.org/10.3327/ taesj2002.2.379.

Kitada A (2013) Public opinion on nuclear power generation measured in continuous polls - changes after Fukushima Daiichi Nuclear Power Plant accident over the past 30 years. Nihon-Genshiryoku-Gakkai Wabunronbun Shi (Transactions of the Atomic Energy Society of 
Japan) 12(3): 177-196 (in Japanese), https://doi.org/10.3327/taesj.J12. 039.

Kitayama K (2013) Ko reberu hoshaseihaikibutsu shobun no juyo shiten 1. Denkijyouhou, February, pp. 20-31 (in Japanese)

Kitayama K and Kikura H (2013) Ko reberu hoshaseihaikibutsu shobun no juyo shiten 2. Denkijyouhou, March, pp. 14-31 (in Japanese).

Kitayama K, Ishiguro K, Takeuchi H et al. (2007) Strategy for safety case development: impact of volunteering approach to siting a Japanese HLW repository. In Proceedings of NEA Symposium 'Safety Cases for the Deep Disposal of Radioactive Waste: Where Do We Stand?', Paris, France, pp. 167-175. See https://www.oecd-nea.org/rwm/ reports/2008/ne6319-safety.pdf (accessed 03/11/2019).

Komine H (2004) Simplified evaluation on hydraulic conductivities of sand-bentonite mixture backfill. Applied Clay Science 26: 13-19, https://doi.org/10.1016/j.clay.2003.09.006.

Kondo M (2017) Do you know on March 11th is the day when the nuclear explosion accident happened? Bungeishunjū, 11 March (in Japanese). See http://bunshun.jp/articles/-/1689 (accessed 27/01/2018).

Masaki M (2012) Attitudes towards Nuclear Power Plants after Experiencing the Serious Accident and a 'Summer of Energy Saving'. NHK Broadcasting Culture Research Institute, Tokyo, Japan. See http://www.nhk.or.jp/bunken/english/reports/summary/201201/02.html (accessed 20/01/2018).

Masuda S (2016) Ko reberu hoshaseihaikibutsu o chika fukaku shimau chiso shobun. Radioactive Waste Management Funding and Research Center, Tokyo, Japan (in Japanese). See https://www.rwmc.or.jp/ library/file/RWMC_masuda.pdf (accessed 26/01/2018).

METI (Ministry of Economy Trade and Industry) (2018) Chiso shobun kenkyu kaihatsu ni kansuru zentai keikaku. METI, Tokyo, Japan (in Japanese). See http://www.meti.go.jp/report/whitepaper/data/pdf/ 20180329001 01.pdf (accessed 26/01/2018).

MIC (Ministry of Internal Affairs and Communications) (2000) Act No. 117 of 2000 on Final Disposal of Specified Radioactive Waste. MIC, Tokyo, Japan (in Japanese). See https://elaws.e-gov.go.jp/search/ elawsSearch/elaws_search/lsg0500/detail?lawId=412AC0000000117 (accessed 03/11/2019).

Mikami H, Shono A and Hiroi H (1996) Sodium Leak at Monju (I) Cause and Consequences. Power Reactor and Nuclear Fuel Development Corporation, Ibaraki, Japan, Document No. 1-7. See http://www.aec.go.jp/jicst/NC/senmon/old/koso/siryo/koso01/siryo07. htm (accessed 27/01/2018).

NEA (Nuclear Energy Agency) (1999) OECD/NEA International Peer Review of the Main Report of JNC's H12 Project to Establish the Technical Basis for HLW Disposal in Japan. NEA, Östhammar, Sweden, NEA/RWM/PEER(99)2. See http://www.aec.go.jp/jicst/NC/ senmon/old/backend/siryo/back26/siryo10.htm (accessed 28/01/2018).

NEA (Nuclear Energy Agency) (2012a) Actual Implementation of a Spent Nuclear Fuel Repository in Sweden: Seizing Opportunities. NEA, Östhammar, Sweden, NEA/RWM/R(2012)2. See https://www.oecdnea.org/rwm/docs/2012/rwm-r2012-2.pdf (accessed 28/01/2018).

NEA (Nuclear Energy Agency) (2012b) Geological Disposal of Radioactive Waste: National Commitment, Local and Regional Involvement - a Collective Statement of the OECD Nuclear Energy Agency Radioactive Waste Committee Adopted March 2012. NEA, Östhammar, Sweden, OECD 2012 NEA No. 7082. See https://www. oecd-nea.org/rwm/reports/2012/7082-geo-disposal-statement.pdf (accessed 28/01/2018).

NUMO (Nuclear Waste Management Organization of Japan) (2001) International Technical Advisory Committee (ITAC) Reports. NUMO, Tokyo, Japan. See https://www.numo.or.jp/en/reports/new eng tab03. html (accessed 27/01/2018).

NUMO (2002) The Repository of Site Selection Process. NUMO, Tokyo, Japan. See http://www.numo.or.jp/en/jigyou/new_eng_tab03.html (accessed 27/01/2018).
NUMO (2004a) Development of Repository Concepts for Volunteer Siting Environments. NUMO, Tokyo, Japan, NUMO-TR-04-03. See https:// www.numo.or.jp/en/reports/pdf/RC_040901_FNL.pdf (accessed 26/01/ 2018).

NUMO (2004b) Evaluating Site Suitability for a HLW Repository:

Scientific Background and Practical Application of NUMO's

Siting Factors. NUMO, Tokyo, Japan, NUMO-TR-04-04. See https:// www.numo.or.jp/en/reports/pdf/Level3 SF Final.pdf (accessed 26/01/ 2018).

NUMO (2008) Geological Disposal of TRU Waste. NUMO, Tokyo, Japan. See https://www.numo.or.jp/en/publications/pdf/TRU_200809.pdf (accessed 27/01/2018).

NUMO (2015) Record of the 1st NUMO Technical Advisory Committee (TAC) Meeting Tokyo, 24-26 November 2015. NUMO, Tokyo, Japan. See https://www.numo.or.jp/technology/technological_advisory_ committee/pdf/Record of 1st TAC meeting.pdf (accessed 27/01/ 2018).

NUMO (2017a) Current Status of Other Countries about the Management for HLW. NUMO, Tokyo, Japan. See https://www.numo. or.jp/chisoushobun/overseas/efforts.html (accessed 21/03/2019) (in Japanese).

NUMO (2017b) Nationwide Map of Scientific Features for Geological Disposal. NUMO, Tokyo, Japan. See http://www.numo.or.jp/ kagakutekitokusei map/pdf/kagakutekitokuseimap.pdf (accessed 25/ 09/2017)

NUMO (2017c) On the Publication of the 'Nationwide Map of Scientific Features for Geological Disposal'. NUMO, Tokyo, Japan. See http://www.numo.or.jp/en/what/topics_170801.html (accessed 25/ 09/2017).

NUMO (2017d) TOPAZ Project: Long-term Tectonic Hazard to Geological Repositories - Toward Practical Application of the ITM-TOPAZ Methodology. NUMO, Tokyo, Japan, NUMO TR16-04 See https://www.numo.or.jp/en/reports/pdf/TR-16-04.pdf (accessed 26/01/2018)

PNC (Power Reactor and Nuclear Fuel Development Corporation) (1992) Research and Development on Geological Disposal of High-level Radioactive Waste: First Progress Report. PNC, Ibaraki, Japan, PNC TN 1410 93-059.

Saigo T, Komatsuzaki S and Horii H (2010) Decisive factors of the dispute regarding high-level radioactive waste repository sitting at Toyo-cho, Kochi, Japan: an analysis of political process and possible solutions. Syakai-Gijyutsu-Kenkyu-Ronbunsyu (Sociotechnica) 7: 87-98 (in Japanese).

SKB (Swedish Nuclear Fuel and Waste Management Company) (2017) Monitoring Forsmark - Evaluation and Recommendations for Programme Update. SKB, Stockholm, Sweden, TR-15-01.

Tashima Y (2008) Nuclear Energy War in a Small Town No One Knew. Wac, Tokyo, Japan (in Japanese).

Tochiyama O and Masuda S (2013) Building technical and social confidence in the safety of geological disposal in Japan. Journal of Nuclear Science and Technology 50(7): 665-673, https://doi.org/10. 1080/00223131.2013.799398.

Van Wart M (2003) Public-sector leadership theory: an assessment. Public Administration Review 63(2): 214-228, https://doi.org/10.1111/ 1540-6210.00281.

Vira J (2006) Winning citizen trust: the siting of a nuclear waste facility in Euraioki, Finland. Innovations: Technology, Governance, Globalization 1(4): 67-82, https://doi.org/10.1162/itgg.2006.1.4.67.

Vogel R and Masal D (2015) Public leadership: a review of the literature and framework for future research. Journal of Public Management Review 17(8): 1165-1189, https://doi.org/10.1080/14719037.2014.895031.

Wada R, Tanaka S and Nagasaki S (2009) Social acceptance process model for ensuring the high-level radioactive waste disposal site Nihon-Genshiryoku-Gakkai Wabunronbun Shi (Transactions of the 
Atomic Energy Society of Japan) 8(1): 19-33 (in Japanese), https://doi. org/10.3327/taesj.J08.015.

Wakasugi K, Ishiguro K, Ebashi T et al. (2012) A methodology for scenario development based on understanding of long-term evolution of geological disposal systems. Journal of Nuclear Science and Technology 49(7): 673-688, https://doi.org/10.1080/00223131.2012.693884.
Yoshida H, Nagatomo A, Oshima A and Metcalfe R (2014) Geological characterisation of the active Atera Fault in central Japan: implications for defining fault exclusion criteria in crystalline rocks around radioactive waste repositories. Engineering Geology 177: 93-103, https://doi.org/10.1016/j.enggeo. 2014.05.008.

\section{How can you contribute?}

To discuss this paper, please submit up to 500 words to the editor at journals@ice.org.uk. Your contribution will be forwarded to the author(s) for a reply and, if considered appropriate by the editorial board, it will be published as a discussion in a future issue of the journal. 